\title{
KOMPOSISI FLORISTIK TINGKAT POHON PADA BAGIAN TIMUR KAWASAN HUTAN DENGAN TUJUAN KHUSUS (KHDTK) HUTAN DIKLAT LOA HAUR TAMAN HUTAN RAYA (TAHURA) BUKIT SOEHARTO
}

\author{
Sugeng Jinarto ${ }^{1}$ \\ ${ }^{1}$ Balai Diklat Lingkungan Hidup dan Kehutanan Samarinda. J1. Untung Suropati Sei \\ Kunjang Samarinda, Indonesia. \\ E-Mail: sugeng.jinarto@gmail.com
}

\begin{abstract}
ABSTRAK
Komposisi Floristik Tingkat Pohon Pada Bagian Timur Kawasan Hutan Dengan Tujuan Khusus (KHDTK) Hutan Diklat Loa Haur Taman Hutan Raya (TAHURA) Bukit Soeharto. Setelah beberapa dekade mengalami berbagai gangguan baik oleh kebakaran hutan dan gangguan kerusakan lainnya, diduga bahwa KHDTK Hutan DiklatLoa Haur telah mengalami berbagai perubahan dalam komposisi floristik tingkat pohon. Untuk itu perlu dilakukan penelitian yang mengarah pada komposisi dan dominasi spesies untuk menentukan tingkat perubahan masyarakat tumbuhan yang terjadi. Suksesi primer adalah perkembangan vegetasi mulai dari habitat yang tidak bervegetasi hingga mencapai komunitas yang stabil atau klimaks, suksesi sekunder adalah suksesi yang terjadi apabila komunitas stabil atau klimaks terganggu atau dirusak baik karena perladangan, kebakaran dan karena bentuk-bentuk kerusakan lainnya

Penelitian ini dilakukan pada tanggal 20-24 Juni 2019 dengan objek penelitian vegetasi tingkat pohon (diameter $\geq 20 \mathrm{~cm}$ ) di KHDTK Hutan Diklat Loa Haur. Alat Penelitian: Sistem Satelit Navigasi Global (GNSS) / GPS), Parang, Kompas, Roll Meters, Phi Band, Alat Tulis, haga meter, dan Kamera untuk dokumentasi. Metode penelitian dilakukan dengan Analisis Vegetasi tanpa Plot dengan Metode Kuadran (Point Quarter Method).

Hasil analisis vegetasi menunjukkan: dari 50 plot/stasiun diperoleh data 157 individu dan 16 spesies tegakan tingkat pohon yang didominasi oleh Acacia mangium, hal ini menunjukkan bahwa jalur penelitian yang diambil adalah pada jalur yang telah ditanam atau reboisasi setelah Bukit Soeharto mengalami kebakaran. Nilai kedua dari Indeks Nilai Penting (INP) adalah jenis lokal dan pioner yang mampu bertahan hidup dan memiliki umur panjang, yaitu dari Genus Litsea, sedangkan INP ketiga dari spesies non-lokal, kemudian INP keempat dan seterusnya adalah spesies lokal lagi yaitu Genus Vitex dan Syzigium. Perlu pengayaan jenisjenis lokal danperlu penelitian lanjutan untuk mengetahui berapa lama spesies lokal dapat mendominasi lagi di lokasi tersebut.
\end{abstract}

Kata kunci : Suksesi, dominanansi, tingkat pohon.

\begin{abstract}
Floristic Composition of Tree Level in the East of Forest Area with Special Purpose of Loa Haur,Forest Park Botanical Garden. After several decades of experiencing various disturbances both by forest fires and other damage disorders, it is suspected that the KHDTK (Training Forest) Loa Haur has undergone various changes in tree-level floristic composition. For this reason, it is necessary to conduct research that leads to species composition and dominance to determine the level of change in plant societies that occurs. Primary succession is the development of vegetation ranging from non-vegetated habitats to reaching stable communities or climaxes, secondary succession is succession that occurs when communities are stable or climax disturbed or damaged either due to inflammation, fires and due to other forms of damage. The study was conducted on June 20-24, 2019 with the object of research on tree-level vegetation (diameter $\geq 20 \mathrm{~cm}$ ) in the KHDTK Loa Haur. Research Tools: Global Navigation Satellite System (GNSS) / GPS), Machetes, Compasses, Roll Meters, Phi band, Writing Instruments, haga meters, and Cameras for
\end{abstract}


documentation. The research method was carried out by Analysis of Vegetation without Plot by Quadrant Method (Point Quarter Method).

Vegetation analysis results show: from 50 plots / stations obtained data of 157 individuals and 16 species of tree-level stands dominated by Acacia mangium, it shows that the research path taken is on the path that has been planted or reforestation after the Bukit Soeharto experienced fire. The second value of Important Value Index (IVI) are local and pioneers that are able to survive and have a long life, namely from the Genus Litsea, but the third value of IVI from non local species, while the fourth value of IVI and so on are the local species again namely Genus Vitex and Syzigium. It is necessary to enrich local species and further research is needed to find out how long local species can dominate again in that location.

Key words : Succession, dominant, tree.

\section{PENDAHULUAN}

Hutan di Kalimantan telah mengalami beberapa gangguan yang menimbulkan kerusakan yang sebagian besar dikarenakan oleh ulah manusia yaitu diantaranya illegal logging, perambahan kawasan, perburuan liar, penambangan illegal dan kebakaran hutan, sedangkan yang disebabkan oleh faktor alam sangat kecil kemungkinan terjadi oleh karena tidak adanya gunung berapi serta adanya petir yang tanpa disertai hujan. Khusus untuk kebakaran hutan, di Kalimantan telah terjadi beberapa kebakaran hutan hebat pada tahun 1982, 1983, 1997 dan 1998 akibat adanya gejala el nino. Kebakaran hutan hebat ini telah melanda beberapa kawasan hutan di Kalimantan yang salah satunya adalah Taman Hutan Raya (Tahura) Bukit Soeharto.

Kawasan Hutan Dengan Tujuan Khusus (KHDTK) Hutan Diklat Loa Haur, merupakan salah satu KHDTK yang terletak di dalam Tahura Bukit Soeharto yang dikelola oleh Balai Diklat Lingkungan Hidup dan Kehutanan Samarinda yang diperuntukkan bagi kegiatan pendidikan dan pelatihan dalam rangka peningkatan kapasitas sumberdaya manusia khususnya pada kegiatan praktik lapang pada suatu kawasan hutan.

Setelah beberapa puluh tahun mengalami berbagai gangguan baik oleh kebakaran hutan maupun gangguan kerusakan lainnya, maka diduga KHDTK
Hutan Diklat Loa Haur telah mengalami berbagai perubahan komposisi floristik/ tumbuhan tingkat pohon. Perubahan ini terjadi bisa saja secara alami yang disebut sebagai suksesi, maupun dengan bantuan manusia dengan adanya penanaman di program reboisasi.

Menurut Anonim, 1992, dalam ilmu ekologi dikenal suatu proses suksesi tumbuhan yang dikendalikan oleh berbagai hukum alam, dan berakhir pada suatu stadia klimaks/puncak yang seimbang secara dinamis dengan lingkungannya. Suksesi adalah suatu rangkaian perubahan masyarakat tumbuhan (komposisi dan struktur) bersamaan dengan perubahan habitat tempat tumbuhnya, terutama iklim mikro dan tanahnya.

Suksesi dapat berjalan maju, yaitu mulai dari keadaan terbuka tanpa tumbuhan, hingga mencapai tahap klimaks setelah melalui tahapan tumbuhan pionir, dan jenis-jenis tumbuhan berikutnya yang lebih toleran terhadap keadaan lingkungannya. Akan tetapi suksesi dapat juga maju-mundur, karena dalam perjalanan atau pertumbuhannya, seperti kebakaran secara periodik di padang alang-alang (Imperata cylindrica). Juga ada perbedaan antara suksesi primer (dari Substrata terbuka dan batuan) dan suksesi sekunder, yaitu dimulai dari substrata yang sudah ada dan mapan, seperti areal bekas tebangan atau perladangan berpindah. 
Dalam rangka mengetahui komposisi floristik khususnya tingkat pohon pada saat ini khususnya pada KHDTK Hutan Diklat Loa Haur, maka perlu dilakukan penelitian yang mengarah pada komposisi dan dominansi jenis untuk mengetahui tingkat perubahan masyarakat tumbuhan yang terjadi, sehingga dapat diketahui jenis tumbuhan mana yang mampu bertahan hidup dan mendominasi pada areal tersebut. Faktor pendukung seperti halnya jenis tanah, kelerengan serta tingkat kesuburan juga berkorelasi dengan dominasi jenis tumbuhan tertentu. Tujuan Penelitian adalah: Mengetahui komposisi tegakan hutan tingkat pohon. Untuk mengetahui jenis yang mendominansi tingkat pohon. Untuk mengetahui potensi tegakan hutan antara lain jumlah individu per jenis, luas bidang dasar per jenis, volume per jenis.

\section{METODA PENELITIAN}

2.1. Tempat dan Waktu

Penelitian dilaksanakan pada sekitar demplot agroforestry KHDTK Hutan Diklat Loa Haur Bukit Soeharto (sebelah timur). Pada bulan Mei-Juni 2019.

\subsection{Objek Penelitian}

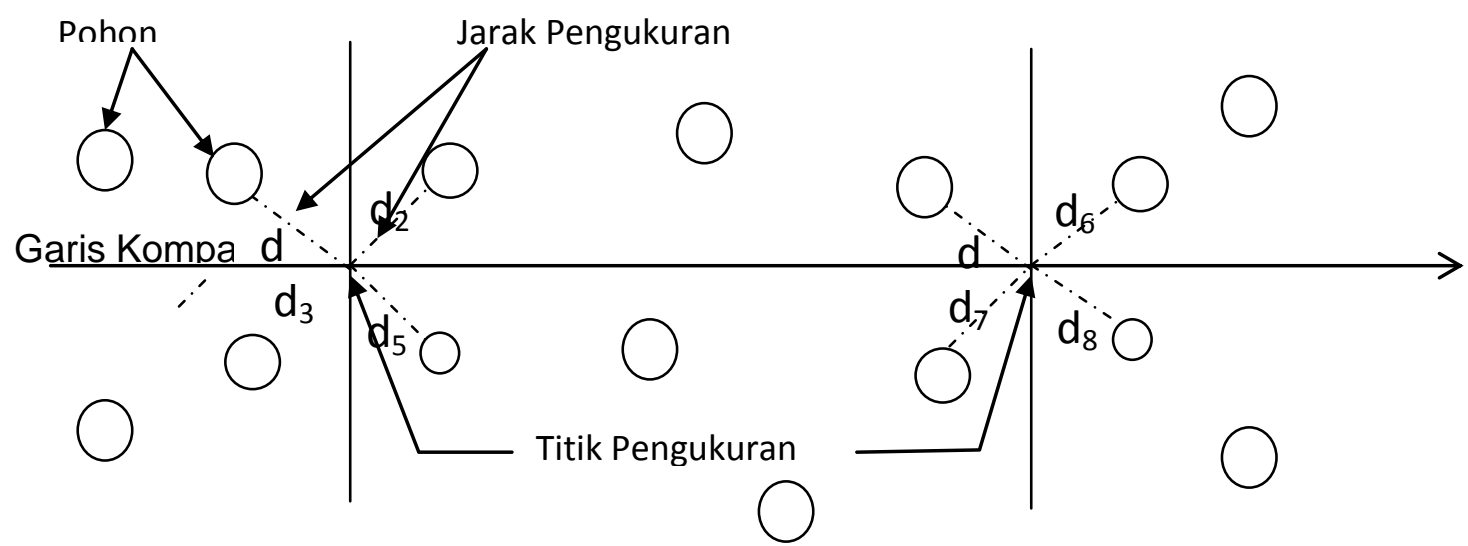

Gambar 2. Pendataan dan pengukuran pohon pada masing-masing kuadran di tiap-tiap Plot/ Stasiun
Objek dari penelitian ini adalah vegetasi tingkat pohon (berdiameter $\geq 20 \mathrm{~cm}$ ) yang terdapat pada areal Hutan KHDTK Hutan Diklat Loa Haur.

\subsection{Alat Penelitian}

Global Navigation Satellite System (GNSS)/ GPS, Parang, Kompas, Meteran, Pita diameter, Alat Tulis menulis, Haga meter, Kamera untuk dokumentasi.

\subsection{Metode Penelitian}

Metode Penelitian dilakukan dengan Analisis VegetasiTanpa Petak dengan Cara Kuadran (Point Quarter Method) Awal kegiatan dilakukan denganmembuat garis kompas. Pada tiap titik pengamatan/ stasiun (pengukuran), dibuat garis-garis kuadran (4 kuadran). (Dalam pelaksanaannya, hanya dibayangkan adanya garis-garis itu). Dari tiap kuadran dilakukan pendataan dan diukur satu pohon yang terdekat dengan titik pengukuran, dan diukur jaraknya masing-masing ke titik pengukuran seperti gambar 2 di bawah ini : 
Dari hasil-hasil pengukuran dihitung besar-besaran sebagai berikut :

Jarak pohon rata-rata :

$$
\begin{aligned}
& \mathrm{D}=\frac{\mathrm{d} 1+\mathrm{d} 2+\mathrm{d} 3+\cdots \ldots \ldots \ldots . \mathrm{dn}}{n} \\
& \mathrm{~d}_{1} \ldots \ldots \ldots \mathrm{d}_{\mathrm{n}}=\text { jarak masing-masing } \\
& \mathrm{n}=\text { banyaknya pohon }
\end{aligned}
$$

Kerapatan seluruh jenis $=$

$\frac{\text { Lwas }}{\text { Uarak pohon rata-rata) })^{2}}$

Kerapatan seluruh jenis/ha $=$

$$
10.000
$$

$\overline{3.1416 \approx(J a n a k \text { pohon rata-nata) }}$

Kerapatan relatif $(\%)=$ $\frac{\text { Jumlah pohon sesuatu jenis }}{\text { Jumlah pohon semua jenis }} \times 100 \%$

Kerapatan $=$

Kerayatan relatif dari swatu jenis 100

Dominansi rata-rata tiap jenis

(Dmr)

$=\frac{\text { Jumlah Wolwme Pohon Swatu Jenis }}{\text { Jumlah Pohon Swatu Jenis }}$

Dominansi $=$ kerapatan dari suatu jenis $\mathrm{x}$ dominansi rata-rata tiap jenis.

Dominansi relatif $(\%)=$

$\frac{\text { Jumlah bidang dasar dari swatu jemis }}{J \text { wmlah selurwh plot }} \times 100$

Frekwensi (F)

$=$

Jumlah Plot (Stasiun) ditemukannya suatu jemis Jumlah semwa Plot (Stasiun)

Frekuensi relatif (\%)

$=\frac{\text { Frekwensi dari swatu jenis }}{\text { Frekwensi selurwh jenis }} \times 100$
Menurut Soerianegara (1978), untuk menentukan Nilai Penting Jenis maka digunakan

rumus : = Kerapatan relatif + dominansi relatif + frekuensi relatif

Luas bidang dasar adalah besarnya luasan penampang batang pohon dengan rumus:

$$
L B D=1 / 4 \pi d^{2}
$$

\section{HASIL PENELITIAN DAN PEMBAHASAN}

Hasil analisis vegetasi menunjukkan bahwa dari 50 plot/ stasiun yang dibuat, diperoleh data sebanyak 157 individu dan 16 jenis tegakan tingkat pohon. Hasil perhitungan kerapatan, kerapatan relatif, frekwensi, frekwensi relatif, dominasi, dominasi

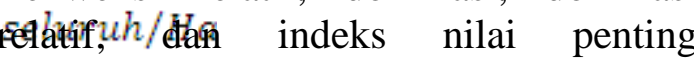
sebagaimana dilihat pada Tabel 1. Data tersebut menunjukkan komposisi dan struktur tumbuhan yang nilainya bervariasi pada setiap jenis karena adanya perbedaan karakter masing-masing pohon. Menurut Kimmins (1987 dalam Arrijani dkk, 2006), variasi struktur dan komposisi tumbuhan dalam suatu komunitas dipengaruhi antara lain oleh fenologi, dispersal, dan natalitas. Keberhasilannya menjadi individu baru dipengaruhi oleh vertilitas dan fekunditas yang berbeda setiap spesies sehingga terdapat perbedaan struktur dan komposisi masing-masing spesies.

Menurut Jayadi (2015) para ahli ekologi menyatukan Konsep Gabungan Faktor Pembatas yaitu Faktor Biotik dan Faktor Abiotik. Dengan konsep seperti ini, maka keragaman tumbuhan dipahami sebagai hasil dari multifaktor. Tidak saja faktor biotik tetapi juga faktor abiotik, termasuk peran manusia di dalamnya. 
Vegetasi tingkat pohon yang didominasi oleh jenis Acacia mangium menunjukkan bahwa jalur penelitian yang dilalui adalah pada jalur yang telah dilakukan penanaman atau reboisasi setelah bukit Soeharto mengalami kebakaran hebat pada tahun 1982, 1983,
1997, 1998. Sehingga peran manusia cukup terlihat dalam proses keberadaan jenis Acacia mangium yang terdapat dan menjadi dominan di daerah tersebut. Jalur penelitian tersebut sebagaimana tertuang di peta pada gambar 3 berikut ini.

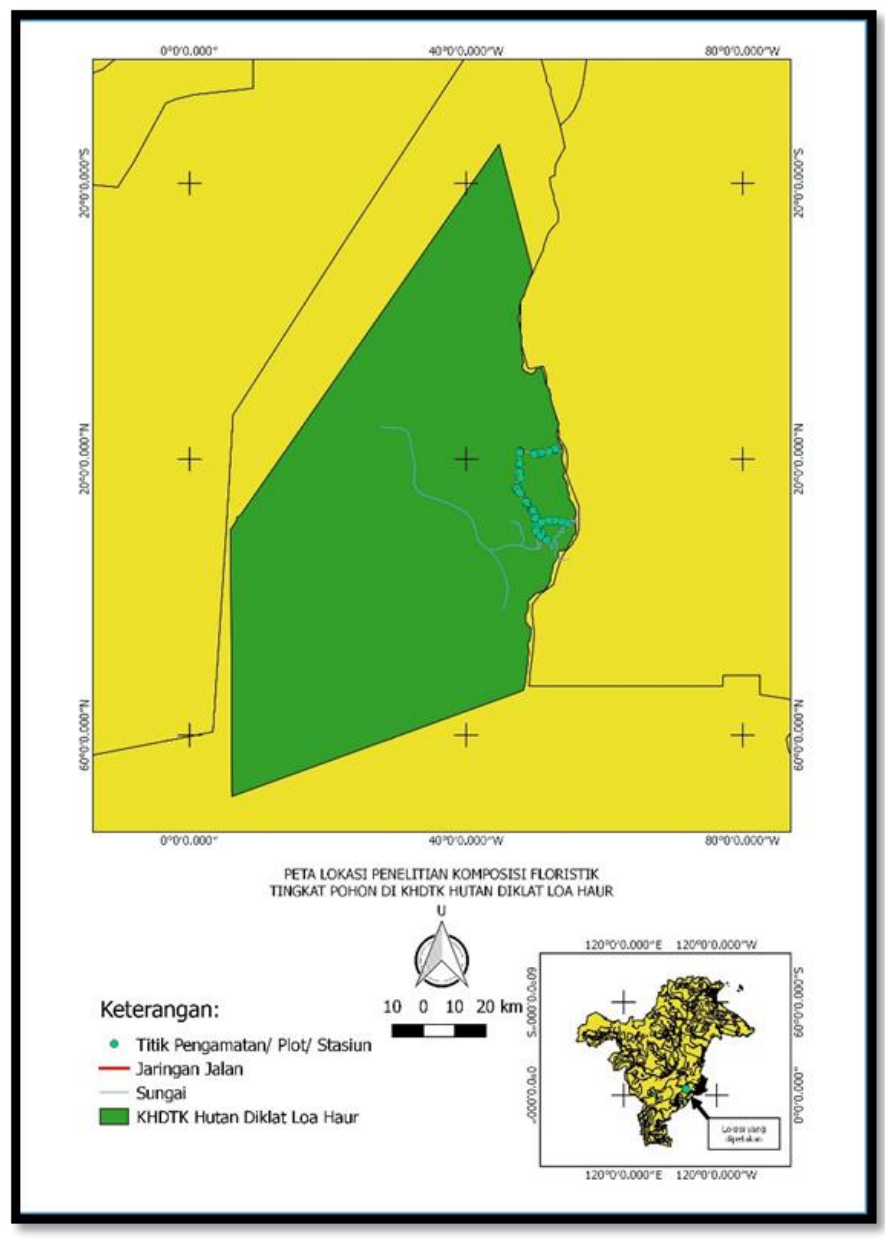

Gambar 3. Peta Lokasi Penelitian

Lebih lanjut menurut Jayadi, 2015. Ada banyak spesies tumbuhan yang dapat digunakan untuk berbagai keperluan indikator yang berkaitan dengan karakteristik lingkungan. Pengetahuan tentang indikator tumbuhan dapat digunakan untuk berbagai kepentingan, di antaranya: membantu mencirikan sifat tanah setempat, mencirikan lingkungan yang tercemar, dan dapat digunakan untuk memperkirakan potensi sumberdaya lahan: untuk hutan, padang rumput atau tanaman pertanian. Tanaman Acacia merupakan tanaman indikator dengan karakteristik lingkungan tanah yang kandungan air tanahnya rendah.

Menurut Sutedjo dan Warsudi, 2017. Spesies Acacia mangium, bukan tergolong species yang bersifat invasif, karena sifat dominan terkait kolonisasinya bersifat sementara dan masih toleran bagi tumbuhnya jenis lokal. Penggunaan atau penanaman spesies Acacia mangium tidak perlu dihindari 
apalagi dicegah, terutama untuk mengatasi lahan kritis alang-alang baik

pada kawasan kritis hutan maupun hutan reklamasi pasca tambang

Tabel 1. Nilai INP jenis-jenis individu tegakan tingkat pohon yang ditemukan pada Bagian Sebelah Timur KHDTK Hutan Diklat Loa Haur

\begin{tabular}{|c|c|c|c|c|c|c|c|c|c|c|}
\hline No & Jenis & $\mathbf{n}$ & $\mathbf{F}$ & FR & $\begin{array}{c}\text { Ka } \\
\text { Pohon/ha }\end{array}$ & KR & Dmr & $\begin{array}{c}\text { D } \\
\text { M2/ha }\end{array}$ & DR & INP \\
\hline 1 & Acacia mangium & 46 & 0.32 & 19.75308642 & 13.3386 & 29.2994 & 0.081605945 & 1.08850709 & 29.8710 & 78.9234 \\
\hline 2 & $\begin{array}{l}\text { Litsea } \text { sp. } \\
\text { Falcataria }\end{array}$ & 27 & 0.30 & 18.51851852 & 7.82916 & 17.1975 & 0.074945341 & 0.58675936 & 16.1019 & 51.8179 \\
\hline 3 & moluccana & 12 & 0.12 & 7.407407407 & 3.47963 & 7.64331 & 0.154638715 & 0.53808527 & 14.7662 & 29.8169 \\
\hline 4 & Vitex pinnata & 14 & 0.18 & 11.11111111 & 4.05957 & 8.91720 & 0.048623400 & 0.19738993 & 5.41680 & 25.4451 \\
\hline 5 & $\begin{array}{l}\text { Syzygium sp. } \\
\text { Artocarpus }\end{array}$ & 12 & 0.14 & 8.641975309 & 3.47963 & 7.64331 & 0.067992733 & 0.23658945 & 6.49252 & 22.7778 \\
\hline 6 & rigidus & 11 & 0.12 & 7.407407407 & 3.18966 & 7.00637 & 0.070471800 & 0.22478104 & 6.16847 & 20.5822 \\
\hline $\begin{array}{l}7 \\
8\end{array}$ & $\begin{array}{l}\text { Dryobalanops } \\
\text { lanceolata } \\
\text { Eusideroxylon }\end{array}$ & 6 & 0.06 & 3.703703704 & 1.73981 & 3.82166 & 0.098580790 & 0.17151226 & 4.70666 & 12.2320 \\
\hline & $\begin{array}{l}\text { zwageri } \\
\text { Macaranga }\end{array}$ & 5 & 0.06 & 3.703703704 & 1.44985 & 3.18471 & 0.131978616 & 0.19134856 & 5.25101 & 12.1394 \\
\hline 9 & $\begin{array}{l}\text { gigantea } \\
\text { Neolamarkia }\end{array}$ & 5 & 0.08 & 4.938271605 & 1.44985 & 3.18471 & 0.065423820 & 0.09485441 & 2.60301 & 10.7260 \\
\hline 10 & cadamba & 5 & 0.06 & 3.703703704 & 1.44985 & 3.18471 & 0.074334183 & 0.10777306 & 2.95752 & 9.84594 \\
\hline 11 & $\begin{array}{l}\text { Ficus sp. } \\
\text { Macaranga }\end{array}$ & 3 & 0.06 & 3.703703704 & 0.86991 & 1.91083 & 0.046004805 & 0.04001991 & 1.09823 & 6.71276 \\
\hline 12 & $\begin{array}{l}\text { hypoleuca } \\
\text { Strobocalyx }\end{array}$ & 3 & 0.04 & 2.469135802 & 0.86991 & 1.91083 & 0.060240180 & 0.05240336 & 1.43806 & 5.81802 \\
\hline 13 & arborea & 3 & 0.02 & 1.234567901 & 0.86991 & 1.91083 & 0.038222800 & 0.03325029 & 0.91246 & 4.05785 \\
\hline 14 & $\begin{array}{l}\text { Schima wallichii } \\
\text { Baccaurea }\end{array}$ & 2 & 0.02 & 1.234567901 & 0.57994 & 1.27389 & 0.085530060 & 0.04960214 & 1.36119 & 3.86964 \\
\hline 15 & $\begin{array}{l}\text { stipulata } \\
\text { Sindora }\end{array}$ & 2 & 0.02 & 1.234567901 & 0.57994 & 1.27389 & 0.034714680 & 0.02013236 & 0.55248 & 3.06093 \\
\hline 16 & wallichii & 1 & 0.02 & 1.234567901 & 0.28997 & 0.63694 & 0.038013360 & 0.01102270 & 0.30249 & 2.17400 \\
\hline & JUMLAH & 157 & 1.62 & 100 & & 100 & & 3.644031186 & 100 & 300 \\
\hline
\end{tabular}

Keterangan: $\mathrm{n}=$ jumlah individu per jenis, $\mathrm{F}=$ Frekuensi, $\mathrm{FR}=$ Frekuensi relative, Ka $=$ Kerapatan Pohon per hektar, KR $=$ Kerapatan Relatif, Dmr $=$ Dominansi rata-rata tiap jenis, D $=$ Dominansi Suatu Jenis, DR $=$ Dominansi Relatif, INP $=$ Indeks Nilai Penting Jenis

INP ke dua adalah jenis lokal dan pioner yang mampu bertahan hidup serta mempunyai umur panjang (long life species) yaitu Genus Litsea, sedangkan yang ke tiga adalah jenis dari luar Kalimantan, kemudian yang ke empat dan seterusnya disusul lagi oleh jenisjenis lokalyang diantaranya adalah dari genus Vitex dan Syzigium. Keberadaan jenis lokal tersebut menandakan bahwa suksesinya baru mencapai pada tipe hutan sekunder muda dan hal ini juga menunjukkan bahwa jenis Acacia mangium masih mempunyai toleransi terhadap jenis lokal untuk tumbuh dengan baik. Menurut Yusuf (2005 dalam Kuspradini, dkk, 2018). Secara ekologi anggota dari jenis lokal genus Litsea mempunyai kemampuan adaptasi dan toleransi relatif lebih baik dibandingkan jenis lain.

Pada lokasi pasca kebakaran terdapat jenis-jenis Litsea yang tumbuh, seperti $L$. elliptica, L. ferruginea, $L$. firma, L. grandis, L. resinosa, L. robusta, Litsea spp, L. angulata, L. garciae, $L$. odorifera, L. ochrea, dan L. caulocarpa (Otto,2006; Purnomo dkk, 2015 dalam Kuspradini, dkk, 2018)

Kebakaran Hutan yang melanda pada kawasan ini memiliki dampak baik positif (menguntungkan) maupun negatif (merugikan). Menurut Jayadi, 2015. Pengaruh kebakaran hutan yang 
menguntungkan berupa: 1)mengurangi potensi bahan bakar, pembakaran terkendali yang dilakukan secara periodik untuk mengurangi potensi bahan bakar sehingga dapat menghindarkan kebakaran yang lebih besar, 2) memperbaiki keadaan habitat dan menyediakan sumber makanan yang baik bagi satwa, 3) menekan serangan hama dan penyakit melalui eradikasi, 4) abu hasil proses pembakaranakan meningkatkan $\mathrm{pH}$ tanah hutan yang pada umumnyabersifat masam, sehingga dapat mengurangi serangan hama dan penyakit yang tidak menyukai kondisi tersebut, 5) mempercepat pertunasan, adanya api akan menstimulasi bakal tunas yang dorman untuk tumbuh. Pertumbuhan tunas setelah kebakaran biasanya berhubungan dengan umur tanaman, ukuran batang, musim, frekuensi kebakaran dan kekerasan kebakaran, 6)membantu penyebaran, jenis-jenis Pinus umumnya menyimpan bijinya dengan mekanisme tertentu di dalam kerucut yang terbalut oleh bahan resin yang sensitif terhadap api sehingga sulituntuk diambil. Dengan adanya api, buah pinus akan membukadan mengeluarkan bijinya, 7) membantu perkecambahan biji, biji yang tersimpan di dalam tanah perkecambahannya dapat distimulasi oleh adanya panas dari api.

Dampak merugikan kebakaran hutan menurut Kantor Meneteri Negara lingkungan hidup, di antaranya: 1) terhadap lingkungan isik, antara lain meliputi penurunan kualitas udaraakibat kepekatan asap yang memperpendek jarak pandang sehingga mengganggu transportasi, mengubah sifat fisikakimiadan biologi tanah, mengubah iklim mikro akibat hilangnya tumbuhan, bahkan dari segi lingkungan global ikut memberikan andil terjadinya efek rumah kaca; 2) terhadap lingkungan hayati antara lain menurunnya tingkat keanekaragaman hayati,terganggunya suksesi alami, terganggunya produksi bahan organik dan proses dekomposisi; 3) terhadap aspek kesehatan, antaralain timbulnya asap yang mengganggu kesehatan masyarakat; 4) terhadap aspek sosial, yaitu hilangnya mata pencaharian, rasa keamanan dan keharmonisan masyarakat lokal, 5) terhadap aspek ekonomi, antara lain dibatalkannya jadwal transportasi darat-air dan udara, hilangnya tumbuh-tumbuhan terutama tumbuhan yang mempunyai nilai ekonomis tinggi, biaya pengobatan masyarakat, turunnya produksi industri dan perkantoran, serta anjloknya bisnis pariwisata.

\section{KESIMPULAN}

Berdasarkan hasil pembahasan dapat ditarik beberapa kesimpulan sebagai berikut : 1) Terjadi perubahan komposisi floristik yang didominasi oleh jenis yang bukan berasal jenis lokal Kalimantan yaitu Acacia mangium. 2) Luas bidang dasar (lbd) pada jenis Acacia mangium mencapai 1,09 $\mathrm{m} 2 / \mathrm{Ha}$ disusul oleh Litsea sp. Sebanyak 0,6 m2/ Ha dan Falcataria moluccana sebesar 0,5 $\mathrm{m} 2 /$ Ha. 3) Tidak perlu adanya kekawatiran akan adanya jenis invasif yang akan menyingkirkan jenis lokal karena pada akhirnya jenis lokal secara perlahan mampu tumbuh dengan baik dengan catatan tidak mengalami gangguan yang secara terus menerus pada jenis tersebut pada proses pertumbuhannya.

\section{DAFTAR PUSTAKA}

Arrijani, Setiadi Dede, Guhardja Edi, Qayim Ibnul. 2006. Analisis Vegetasi Hulu DAS Cianjur Taman Nasional Gunung Gede-Pangrango. BIODIVERSITAS ISSN: 1412- 
033X Volume 7, Nomor 2,April 2006 Halaman: 147-153

Jayadi, E.M. 2015. Ekologi Tumbuhan. Institut Agama Islam Negeri (IAIN) Mataram

Kuspradini, H. Putri, A.S, Diana, R. 2018. Potensi Tumbuhan Genus Litsea. Mulawarman University Press. Samarinda

Sutedjo dan Warsudi, 2017. Menakar Sifat Invasif Spesies Akasia Mangium (Acacia mangium Willd.) di Hutan Penelitian dan Pendidikan Bukit Soeharto. Ulin. Jurnal Hutan Tropis Vol (1) No (1): 82-89 pISSN 2599 1205, eISSN 25991183 Maret $2017 . \quad \mathrm{http}: / / \mathrm{e}-$ journals.unmul.ac.id/index.php/UJ HT/article/view/795 diunduh 1 Agustus 2019

Bratawinata, A.A 1982. Penelitian Mengenai Komposisi Jenis Vegetasi Dari Type Hutan Primer, Hutan Bekas Tebangan, Hutan Sekunder Muda, Hutan Bekas Ladang (belukar) Di Hutan Lindung Bukit Soeharto Samboja, Universitas Mulawarman, Samarinda.

Bratawinata, A.A 1987. Komposisi dan Dominasi Jenis Pada Hutan Primer Bekas Kebakaran Di Hutan Pendidikan Universitas Mulawarman, Taman Hutan Raya Bukit Soeharto, Univesitas Mulawarman, Samarinda.

Bratawinata,A.A 1994. Diktat Dasar Ekologi dan Ekologi Hutan Tropis
Universitas Mulawarman, Samarinda.

Bratawinata, A.A 1998. Ekologi Hutan Hujan Tropis Dan Metoda Analisis Hutan, Universitas Mulawarman, Samarinda.

Kartawinata, K 1975. Suksesi Sekunder dan Perubahan Ekologi Lainnya di Hutan Tropika Setelah Perusakan Oleh Manusia di Kalimantan Timur Universitas Mulawarman, Samarinda.

Richrds, P.W 1964. The Trofical Rain Forest An Ecologycal Study Cambrige Universitas Press Cambrige.

Samingan, 1971. Type-type Vegetasi Bagian Ekologi Tumbuh-tumbuhan Fakultas Kehutanan IPB, Bogor.

Soemarwoto, $\quad$ O 1983. EkologiLingkungan Hidup dan Pembangunan, Djambatan Jakarta.

Soerianegara dan Indrawan 1976. Ekologi Hutan Indonesia, Lembaga Kerjasama Fakultas Kehutanan IPB, Bogor.

Soerianegara dan Indrawan 1978. Pengelolaan Sumber Daya Alam Bagian I Sekolah Pasca Sarjana Pengelolaan Sumber Daya Alam Lingkungan Hidup IPB, Bogor.

Simon, H. 1993. Metode Inventore Hutan. Fakultas Kehutanan. Universitas Gajah Mada. 